\title{
Male Anterior Urethral Stricture: Epidemiological Profile and Management at Ouagadougou University Teaching Hospital (Burkina-Faso)
}

\author{
Clotaire AMKD Yameogoํㅜ, Adama Ouattara ${ }^{2}$, Fasnéwindé A. Kaboré ${ }^{1}$, Bienvenue D. Ky¹, \\ Alexandre Bougayiri ${ }^{1}$, Oumarou Traoré ${ }^{1}$, Timothée Kambou ${ }^{2}$ \\ ${ }^{1}$ Division of Urology, Yalgado Ouedraogo University Hospital, Ouagadougou, Burkina Faso \\ ${ }^{2}$ Division of Urology, Souro Sanou University Hospital, Bobo-Dioulasso, Burkina Faso \\ Email: yameogoclotaire@yahoo.fr
}

How to cite this paper: Yameogo, C.A., Ouattara, A., Kaboré, F.A., Ky, B.D., Bougayiri, A., Traoré, O. and Kambou, T. (2017) Male Anterior Urethral Stricture: Epidemiological Profile and Management at Ouagadougou University Teaching Hospital (Burkina-Faso). Open Journal of Urology, 7, 196-206.

https://doi.org/10.4236/oju.2017.711023

Received: September 3, 2017

Accepted: November 12, 2017

Published: November 15, 2017

Copyright $\odot 2017$ by authors and Scientific Research Publishing Inc. This work is licensed under the Creative Commons Attribution International License (CC BY 4.0).

http://creativecommons.org/licenses/by/4.0/

\begin{abstract}
It was a retrospective and descriptive study conducted in the urology division of Yalgado Ouedraogo University Teaching Hospital from October 2009 to September 2014. Sixty three (63) male patients with anterior urethral stricture disease were included. All the patients have their diagnosis confirmed by voiding retrograde cystourethrogram (VCUG) or during surgical intervention. Anterior urethral stricture constitutes $41.1 \%$ of all urethral stricture. Hospital prevalence was $4.2 \%$. Patient average age was 50.5 years. Dysuria and urinary retention were the major complaints representing respectively $66.7 \%$ and $33.3 \%$. The infectious cause of urethral stricture was $71.1 \%$ of cases, followed by iatrogenic and traumatic causes with respectively $17.4 \%$ and $11.1 \%$ of cases. Voiding retrograde urethrocystogram (VCUG) was the only diagnostic procedure. Single urethral stenosis of the anterior urethra was about $88.8 \%$ while multiple stenosis constituted about $11.2 \%$. Bulbar urethral stricture was the major location for the stenosis. Urine analysis was performed on $82.5 \%$ patients and ruled out urinary infections in $69.2 \%$ of cases with identification and isolation of Escherichia Coli in 77.7\%. Majority of patients (61.9\%) had open surgery of which $39.7 \%$ had end to end resection and anastomosis. Dilatation constituted $33.3 \%$ of treatment of the stricture of the anterior urethra. No endoscopic treatment was registered. At the removal of the catheter, all were successful but with time, the success rate was $87 \%$ at 6 months, $89.7 \%$ at 12 months, $85.2 \%$ at 18 months $63.1 \%$ at 24 months.
\end{abstract}

\section{Keywords}

Male, Urethral Stricture, Management, Epidemiology 


\section{Introduction}

Urethral stricture is a permanent reduction of the lumen of urethra, or even the complete obliteration of its canal, which reduces the urinary flow from the bladder to the exterior whatever the level and the etiology of the stricture. Anterior and posterior urethra's strictures are distinguished. The anterior part of urethra goes from the end of the membranous portion to the urethral meatus. It can be subdivided into bulbar and penile urethra. The symptomatology of urethral stricture is univocal and represented by dysuria or urinary bladder retention. Infectious aetiologies are decreasing in developed countries compared to traumatic and iatrogenic aetiologies [1]. This does not seem to be the case in our context, despite the lack of epidemiological studies. We have conducted a retrospective study in order to highlight the management of the anterior urethra stricture at Ouagadougou university teaching hospital.

\section{Patients and Methods}

It was a retrospective and descriptive study in the urology division of Yalgado Ouedraogo University Teaching Hospital from October 2009 to September 2014. This study included all patients with anterior urethra stricture only confirmed by retrograde urethrography/voiding cystouretrography (VCUG) or during the surgery with a complete medical record. The patients who have not complete medical records and VCUG were excluded to this study. Epidemiological, clinical and managements parameters are studied.

\section{Results}

\subsection{Frequency}

In the period of study, 153 patients present urethral stricture, from whom 63 have presented anterior urethral one. The strictures of the anterior urethra accounted for $41.1 \%$ of all urethral strictures. The hospital prevalence of these strictures among hospitalizations (1507 patients) in the urology department was $4.2 \%$.

\subsection{Age}

The mean age of the patients was 50.5 years with 3 and 81 years extremes. Figure 1 shows the distribution of patients by age group.

\subsection{Reasons of Consultation}

Patients consulted on average after about 6 months. Dysuria and urine retention were the main reasons for consultation with respectively $66.7 \%$ and $33.3 \%$ of cases as presented on Table 1 .

\subsection{Medical and Surgery Histories}

Forty-two (66.6\%) had a history of urinary tract infection. Table 2 showed the different medical and surgical histories of the patients. 


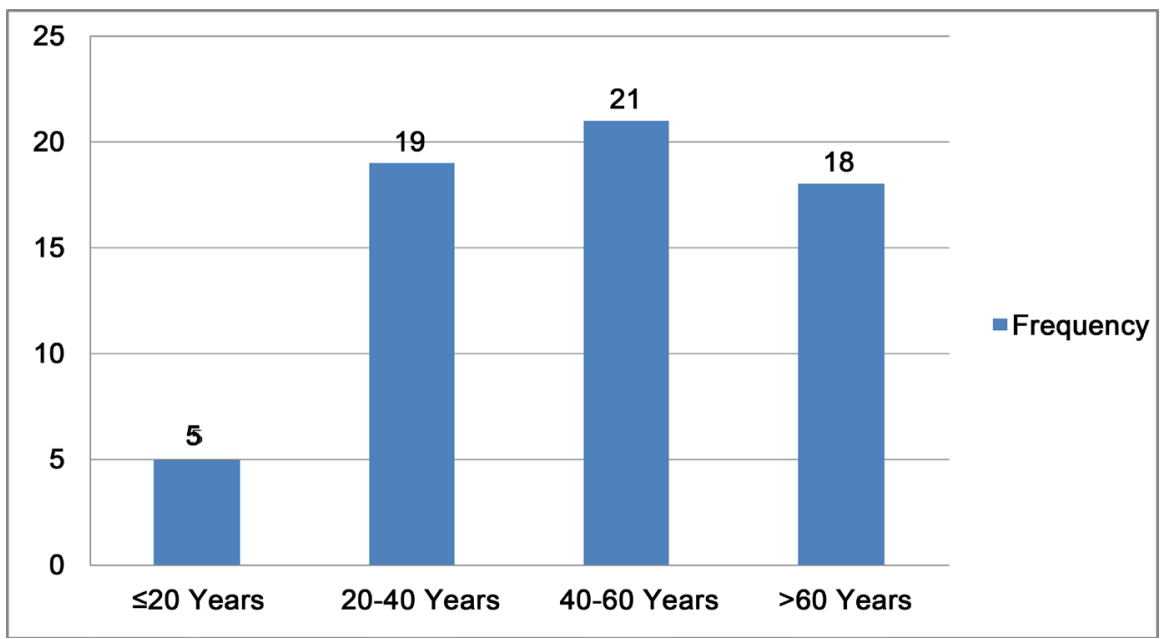

Figure 1. Distribution of patients by group of age.

Table 1. Distribution of patients according to the reasons of consultation.

\begin{tabular}{ccc}
\hline Reasons of consultation & Frequency $^{*}(\mathrm{n})$ & Percentage $^{*}(\%)$ \\
\hline Dysuria & 42 & 66.7 \\
Urinary bladder retention & 21 & 33.3 \\
Urinary Burns & 15 & 23.8 \\
Urinary frequency & 6 & 9.5 \\
Blood at the meatus & 2 & 3.2 \\
Urethral Fistulas & 2 & 3.2 \\
\hline
\end{tabular}

*Some patients have presented one or more reasons of consultation.

Table 2. Distribution of patients according to their medical or surgical histories.

\begin{tabular}{ccc}
\hline Medical/Surgical history & Frequency (n) & Percentage (\%) \\
\hline Lower Urinary Tract Infection & 44 & 66.6 \\
Schistosomiasis & 12 & 19 \\
Urethral trauma & 9 & 14.2 \\
Primary urethral repair & 8 & 12.7 \\
Suprapubic cystostomy & 5 & 7.9 \\
Urethral dilatation & 3 & 4.8 \\
Hypospadias repair & 1 & 1.6 \\
\hline
\end{tabular}

\subsection{Clinical Signs}

On the physical examination, 20 patients had physical signs which are distributed as follows in Table 3.

\subsection{Complications}

Table 4 presents the distribution of the complications to the stricture of the anterior urethra. 
Table 3. Distribution of patients according to the physical signs presented.

\begin{tabular}{ccc}
\hline Clinical signs & Frequency $(\mathbf{n})$ & Percentage (\%) \\
\hline Hypogastric tenderness & 10 & 15.87 \\
Urethral discharge & 8 & 12.7 \\
Urethral and perineum sclerosis & 2 & 3.2 \\
\hline
\end{tabular}

Table 4. Distribution of patients according to complications.

\begin{tabular}{ccc}
\hline Complications & Frequency (n) & Percentages (\%) \\
\hline Suppurative peri-urethritis & 8 & 12.7 \\
Orchiepididymitis & 6 & 9.7 \\
Urethral Fistulas & 5 & 7.9 \\
Prostatitis & 1 & 1.6 \\
\hline
\end{tabular}

Table 5. Distribution of patients according the type of bacteria at urine analysis.

\begin{tabular}{ccc}
\hline Bacteria & Frequency (n) & Percentage $\%$ \\
\hline E. coli & 28 & $77.7 \%$ \\
Klebsiella sp & 9 & $25 \%$ \\
Pseudomonas aeruginosa & 2 & $5.5 \%$ \\
Enterobacter cloacae & 1 & $2.7 \%$ \\
Neisseria gonorrhea & 1 & $2.7 \%$ \\
Staphylococcus saprophyticus & 1 & $2.7 \%$ \\
\hline
\end{tabular}

\subsection{Aetiologies}

The etiology of the anterior urethral stricture was infectious in $71.4 \%$ of cases, followed by iatrogenic and traumatic ones with respectively $17.5 \%$ and $11.1 \%$. The urine analysis performed in $82.5 \%$ patients showed a urinary tract infection in $69.2 \%$ of cases and isolated E. coli in $77.7 \%$ of the cases, shown in Table 5.

\subsection{VCUG Findings}

VCUG was performed in all patients. Stricture of the anterior urethra was unique in the majority of cases (88.8\%) and multiple in $11.2 \%$ of cases. The bulbar seat was their favorite location. The length of strictures averaged $2.05 \pm 0.7$ $\mathrm{cm}$.

\section{- Urethral stricture location}

There were 29 cases of bulbar localization on the $63(46.4 \%)$ and $25(41.6 \%)$ of the penile sites. Table 6 presented the distribution according to the location of the anterior urethral stricture.

Figure 2 and Figure 3 presented respectively bulbar urethral stricture and anterior panurethral stricture on VCUG.

\section{- The number of stricture}

Strictures of the anterior urethra in our series were unique in $88.8 \%(\mathrm{n}=56)$ 
Table 6. Distribution of patients according to the location of stricture on urethra.

\begin{tabular}{ccc}
\hline Stricture location & Frequency (n) & Percentage (\%) \\
\hline Bulbar & 29 & 46.4 \\
1/3 proximal penile urethra & 17 & 26.8 \\
$1 / 3$ distal penile urethra & 6 & 9.5 \\
Junction bulbar and penile urethra & 5 & 7.7 \\
1/3 middle penile urethra & 2 & 3.2 \\
Meatal & 2 & 3.2 \\
Pan anterior urethral & 2 & 3.2 \\
Total & 63 & 100 \\
\hline
\end{tabular}

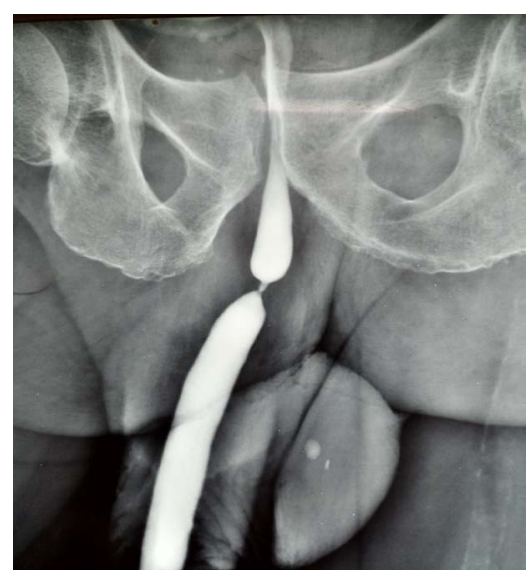

Figure 2. Bulbar urethral stricture on VCUG.

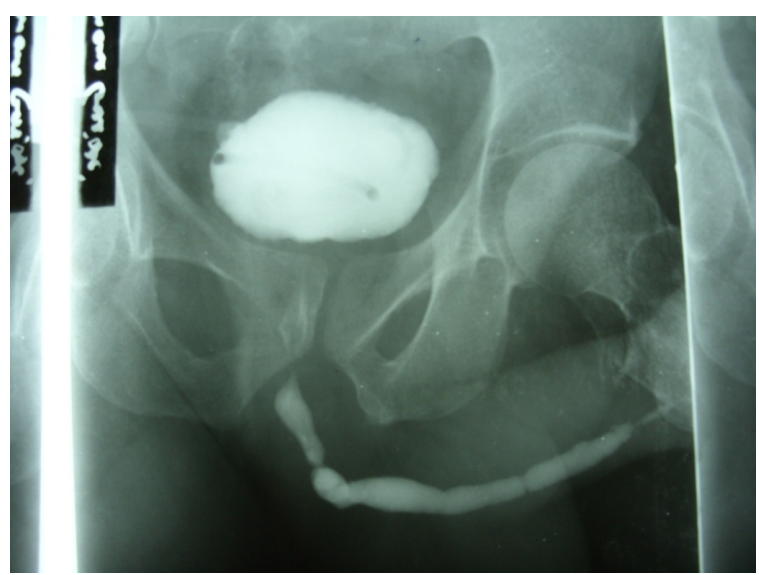

Figure 3. Anterior pan-urethral stricture on VCUG.

of cases and multiples in $11.2 \%$ (7 cases).

\section{- The length of the stricture}

The length of the urethral stricture was less than $1 \mathrm{~cm}$ in 23 cases. In the slices of $1-2 \mathrm{~cm}$ and more than $2 \mathrm{~cm}$ we noticed the same number of cases 16 . The distribution of anterior urethral stricture cases according to their length has been shown in Figure 4. 


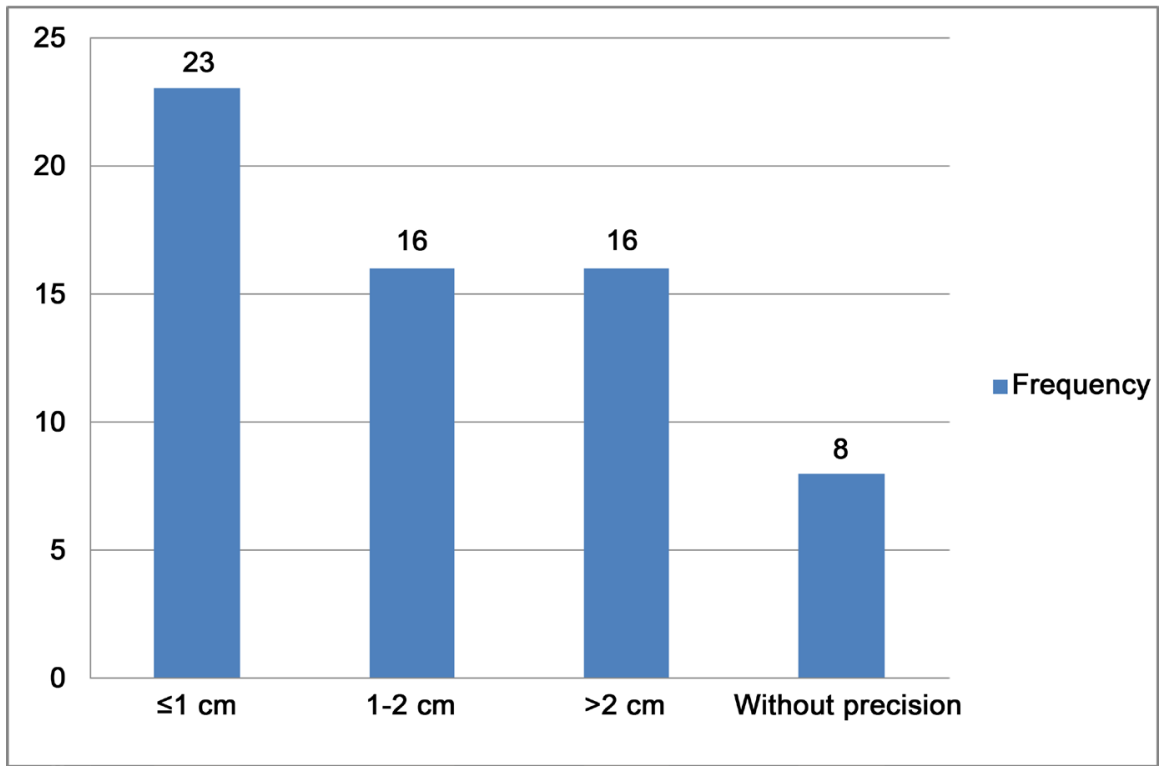

Figure 4. Distribution of patients according to the length of the stricture.

Table 7. Distribution of patients according to technique of surgery performed.

\begin{tabular}{ccc}
\hline Surgical procedure & Frequency (n) & Percentage\% \\
\hline Urethroplasties & 39 & $61.9 \%$ \\
End to end anastomosis & 25 & $39.7 \%$ \\
Mikalowsky repair technique & 6 & $9.5 \%$ \\
Pediculated penile flap & 3 & $4.7 \%$ \\
Bengt Johansen technique & 2 & $3.2 \%$ \\
Meatotomy & 2 & $3.2 \%$ \\
Scrotal flap & 1 & $1.6 \%$ \\
Urethral Dilatation & 23 & $36.5 \%$ \\
Definitive urinary diverting & 1 & $1.6 \%$ \\
Total & 63 & $100 \%$ \\
\hline
\end{tabular}

\subsection{Management}

In emergency 25 patients underwent a suprapubic urinary derivation. 23 by cystostomy and 2 by suprapubic cystocatheterism.

After the emergency management, thirty-nine patients (61.9\%) had prior received urethroplasty and 23 patients (36.5\%) an instrumental treatment by dilatation. Table 7 showed the distribution of patients according to their first treatment received.

The majority of patients (61.9\%) had open surgery. 39.7\% of them were urethrectomy and termino-terminal anastomosis. The instrumental dilatation was about $33.3 \%$ of the treatment of stricture of the anterior urethra. No endoscopic treatment had been recorded. After the urinary catheter removal we recorded a total success but over the time the rates were: $87 \%$ success at 6 months; 
$89.7 \%$ success at 12 months; $85.2 \%$ success at 18 months, $63.1 \%$ success at 24 months, $58.3 \%$ success at 36 months and $33.3 \%$ success at 48 months.

\section{Discussion}

During the study period, the hospital prevalence of the anterior urethral stricture was $4.2 \%$ in the department. Retrospective study by Guiriansoro Z [2] reported a hospital prevalence similar to $3.5 \%$ of urethral stricture. However, Mattiche $\mathrm{H}$ [3] and Fall et al. [4] reported some prevalence higher than ours, respectively $7 \%$ and $6.5 \%$. From this diversity of prevalence we can notice that the stricture of the anterior urethra was one of the causes of hospitalization in urology departments.

In Europe, Lumen $\mathrm{N}$ et al. [5] and Palminteri et al. [6] reported higher rates of anterior urethral stricture respectively $60.9 \%$ and $77.4 \%$. The stricture of the anterior urethra as well as the urethral stricture in general is a pathology of young adult. The mean age in our study was similar to 50.5 years. The slices of $41-60$ years $(33.3 \%)$ and 21 - 40 years $(30.1 \%)$ were the more affected groups. The average age of our patients was similar to those of Zango B et al. [7] and Guirassy et al. [8] who reported respectively an average age of 47.8 and 51.4 years. Heyns et al. [9] in a comparative study also reported averages of 49.9 and 50.9 years. These results confirm the fact that urethral stricture is an affection of the young adult especially in sub-Saharan Africa where the sexual transmitted infections and urethritis are frequent in young people. The high average age in developed countries could be related to a high frequency of endourology therapies at these ages.

In our study, dysuria and acute urinary retention were the most frequent reasons for consultation with respectively $66.7 \%$ and $33.3 \%$ of cases. In the literature, the first reason for consultation of the urethral stricture was dysuria [5] [6]. Other patients consulted for the first time at the complications stage. Guirassy et al. [8], Fall B et al. [4] reported low rates compared to ours respectively $32.4 \%$; and $42.2 \%$. In Zango et al. [7] study, from the 70 patients, 46 (65.7\%) were seen with complications including 34 acute urinary retention, 7 penoscrotal fistulas and 5 genital cellulitis. In Gabon, Falandry [10] reported 29.8\% fistulas from urethral strictures and $50 \%$ of upper urinary tract complications.

Urinary tract infections were the medical history developed by the majority of patients, around $66.6 \%$ of cases. Infections were followed by traumatic urethral catheterism which accounted for $14.2 \%$ of the medical history. Mattiche $\mathrm{H}$ [3] reported a $50 \%$ history of urethritis. These outcomes highlighted the risk for patients with a history of urethritis to develop an anterior urethra stricture. Less than half of the patients had physical signs. The distended bladder was the most frequent sign. In our study, 10 patients of the 63 had a distended bladder $15.8 \%$. Mattiche $\mathrm{H}$ [3] reported distended bladder percentages with $37 \%$ of patients. These results allow us to remember that the physical examination of patients with anterior urethral stricture is poor.

Bulbar localization was the most frequent in our study. We found 29 cases 
(46.4\%) of bulbar strictures, 25 cases (39.5\%) of penile strictures, 2 cases $(3.2 \%)$ of meatus localization and 7 (10.9\%) were multiple localizations on the anterior urethra. In West Africa, Akpo et al. [11] reported bulbar strictures rates close to ours, with 47.3\%. Lumen $\mathrm{N}$ et al. [5] and Palminteri et al. [6] also reported similar rates with respectively $48.1 \%$ and $46.9 \%$ of bulbar strictures. Bulbar localization, although reported at different rates by different authors, was the first place in the location of anterior urethral stricture in both developed and developing countries. This high frequency of localization to the bulbar urethra could be related to the fact that the anatomical bulbar portion is propitious to infections. In our study, $88.8 \%$ of anterior urethral strictures were unique and multiple in $11.2 \%$ of cases similar to Lumen $\mathrm{N}$ et al. [5], who had reported $13.4 \%$. The mean length of the anterior urethral stricture was $2.05 \mathrm{~cm}$ with 1 to $9 \mathrm{~cm}$ as extremes. $36.5 \%(\mathrm{n}=23)$ of patients had a short $(\leq 1 \mathrm{~cm})$ strictures, $25.4 \%(\mathrm{n}=16)$ long strictures $(>2 \mathrm{~cm})$. However, Fenton et al. [12] in a study of the anterior urethra had noticed an average length of urethral stricture greater than ours with $4.1 \mathrm{~cm}$. Palminteri et al. [6] reported an average length of $4.15 \mathrm{~cm}$. From these results, it appeared that a large part of the strictures of the anterior urethra was medium or long. The length of the stricture is one of the criteria for the choice of the therapeutic method. Strictures less than one centimeter in length are most often treated by internal urethrotomy or by an instrumental dilatation. Whereas between one and two $\mathrm{cm}$ in length, a segmental urethrectomy followed by a terminal-terminal anastomosis is necessary.

We have identified 3 groups of etiology in our study: infectious, iatrogenic and traumatic. Our study showed a predominance of infectious etiologies (71.4\%) followed by iatrogenic causes (17.5\%). Traumatic etiology accounted for $11.1 \%$. In our regions, the main etiologies of strictures of the anterior urethra are infectious. In Gabon Falandry [10] found an infectious origin in 52\% of cases. Akpo et al. [11] and Fall et al. [4] noticed the predominance of infectious causes with respective rates of $54.3 \%$ and $63 \%$.

However, Fleury [13] noted in Switzerland a low percentage of infectious cause $11 \%$ compared to iatrogenic causes. This confirms the fact that in developed countries, the iatrogenic etiology is the most important [1]. The infections responsible are usually acute gonococcal urethritis or Chlamydia trachomatis urethritis. We have identified one case of gonorrhea among infectious causes. 12 patients had history of urogenital schistosomiasis. Urogenital tuberculosis endemic in our country has not been identified as an etiology in our patients. Chatelain et al. [14] reported a rare bilharzia cause of urethral stricture in a study conducted in France.

The infectious origins are decreasing in African studies but remain one of the common causes of urethral stricture despite the existence and availability of antibiotics and the different means of sexual transmitted infections prevention.

The iatrogenic etiology accounted for $17.5 \%$ of the anterior urethral stricture etiologies in our study. In developed countries, urethral strictures are more likely to be of iatrogenic origin and could be explained by the fact that urologic en- 
doscopy is a common practice in their context. Fleury [13] had noted $50 \%$ of iatrogenic etiologies. In our study the rate of iatrogenic etiologies could be explained by the increasingly common and abusive practice of urethral catheterism in doubtful asepsis conditions.

Trauma to the anterior urethra represents about $10 \%$ of urogenital trauma. Compared to the lesions of the posterior urethra, these traumas rarely occur in a vital or polytraumatic context and are rarely associated with pelvic fractures. The majority in these cases involve blunt trauma, often affecting young people who are sexual active. From these results, it appears that traumatic etiology was not the main cause in the occurrence of anterior urethral stricture.

The penile urethra stricture corresponds to a phenomenon of fibrosis of the corpus spongiosum whose morphological and functional fate is difficult to predict. The surgical treatment of such lesions is difficult and calls for the general principles of wound healing. Reconstruction of the urethra in its penile portion appears easier than the treatment of proximal strictures or strictures of the bulbar urethra because it is more accessible. In our regions, open surgery is the most commonly used treatment of urethral strictures. The most common method used after urethroplasty in our study was urethral dilatation. Thirty-three percent of the patients had benefited of instrumental dilatation. These results showed a relative decrease in the rate of patients treated only with instrumental dilatation but this rate remains high because our patients treated with urethroplasty may have an ulterior instrumental dilation. We have not noticed either incidents or accidents and none deaths recorded in the immediate or postoperative period. However, at an average follow-up of 12.51 months, $9 \%$ of the patients did not have a good result. Ibrahim Ag et al. [15] reported a lower rate than our (84.6\%) in a study on urethroplasty treatment. At the period of the study, our urology division didn't have endourology equipment, thus we didn't performed any technique of direct visual internal urethrotomy for the management of anterior urethral stricture.

This difference could be explained by the diversity of follow-up delays. The short follow-up time of the patients was related to the non-respect of the appointments after leaving hospital by a large number of patients. All the patients whose strictures were $1 \mathrm{~cm}$ at most have obtained good results after 6 months of follow-up versus $85.7 \%$ for anterior urethral stricture with $[1-2 \mathrm{~cm}]$ and $66.6 \%$ for those $>2 \mathrm{~cm}$. However, our results remain superior to those of Guirassy et al. [8] who reported $81.6 \%$ success for the urethral stricture between 0.5 and $1 \mathrm{~cm}$ and only $18.20 \%$ success for the urethral stricture $>2.5 \mathrm{~cm}$. From these results it appears from the diversity of the success rates that the short urethral stricture had more good results than the long after treatment.

\section{Conclusion}

Anterior urethral stricture is relatively a frequent affection in our urology division. The stricture of the anterior urethra is a pathology of all ages but it's more 
frequent in young's. The most evocative sign is dysuria but urine retention and the complications such as urethral fistulas can constitute the reason for first consultation. The diagnosis remains based on the VCUG and other exploration techniques as uroflowmetry which is not available and is an important element in the postoperative follow-up. The VCUG allowed in all cases to locate the seat, the number of stenosis and to appreciate the length of the stenosis. Aetiologies are dominated by infectious causes with a high predominance of E. coli. Diagnosis at complications stage, poor exercise conditions and the inaccessibility of diagnostic and therapeutic means often make the management difficult. The therapeutic methods are multiple and the therapeutic choice depends on the location, the number and the length of the stricture. The treatment of anterior urethral stricture remains surgical in our context. The better management of urinary tract infections and urethral trauma should be reduced significatively the burden of urethral stricture in our setting.

\section{Conflict of Interest}

There is no conflict of interest.

\section{References}

[1] Ballanger, P., Midy, D., Vely, J.F. and Ballanger, R. (1983) Results of Internal Urethrotomy in the Management of Urethral Stricture. About 72 Observations. The Journal of Urology, 89, 95-99.

[2] Guiriansoro, Z. (2009) Urethral Stricture in Adults at CHUYO. About 60 Cases. Medecine Thesis, University of Ouagadougou, Burkina Faso.

[3] Mattiche, H. (2010) Sclero-Inflamatory Urethral Stricture in Males. About 16 Cases. Medecine Thesis, University of Fès, Morocco.

[4] Fall, B., Sow, Y., Mansouri, I., Sarr, A., Thiam, A., Diao, B., Fall, P.A. et al. (2011) Etiology and Current Clinical Characteristics of Male Urethral Stricture Disease: Experience from a Public Teaching Hospital in Senegal. International Urology and Nephrology, 43, 969-974.

[5] Lumen, N., Hoebeke, P., Willemsen, P., De Troyer, B., Pieters, R. and Oosterlinck, O. (2009) Etiology of Urethral Stricture Disease in 21st Century. The Journal of Urology, 182, 983-987.

[6] Palminteri, E., Berdondini, E., Verze, P., DE Nunzio, C., Vitarelli, A. and Carmignani, L. (2012) Contemporary Urethral Stricture Characteristics in Developed Word. Urology, 81, 191-196.

[7] Zango, B., Kambou, T. and Sanou, A. (2003) Internal Endoscopic Urethrotomy for Urethral Stricture at Bobo-Dioulasso University Hospital: Feasibility of the Technique in Precarious Situations and Short Term Results. Bulletin De La Societe De Pathologie Exotique, 96, 92-95.

[8] Guirassy, S., Simakan, N.F., Balde, A., Sow, K.B., Balde, S., Bah, I., Bah, O.R. and Diallo, M.B. (2001) Post Traumatic Urethral Strictures at Ignace Deen University Teaching Hospital. Retrospective Study of 74 Cases. Annales D'Urologie, 35, 162-166.

[9] Heyns, C.F., Van Der Merwe, J., Basson, J. and Van Der Merwe, A. (2012) Etiology of Male Urethral Stricture. Evaluation of Temporal Change at a Single Center, and 
Review of Literature. African Journal of Urology, 18, 4-9.

[10] Falandry, L. (1991) Techniques and Results of Urethral Strictures Management: One Stage Urethroplasty by Pediculated Skin Graft. Medecine d Afrique Noire, 38, 530-537.

[11] Akpo, E.C., Hodonou, R., Lalyp, R. and Hounnasso, P. (1998) Male Urethral Strictures at CNHU Hospital of Cotonou. About 123 Cases. Le Benin Médical Spécial Urologie, 9, 28-36.

[12] Fenton, A.S., Morey, A.F., Aviles, R. and Garcia, R.C. (2005) Anterior Urethral Stricture: Etiology and Characteristics. Urology, 65, 1055-1058.

[13] Fleury, N.P. (2002) Treatment of Urethral Strictures by Laser. Medicine Thesis, University of Geneva, Geneva.

[14] Chatelain, C., Pechere, J.C., Boccon-Gibod, L. and Richaud, C. (1985) Urethritis in Male. In: Infectious and Parasitary Pathologies, Urologie Ed Masson, Paris, 269-277.

[15] Ibrahim, G.A., Ali, N., Aliyu, S. and Bakaru, A.A. (2012) One-Stage Urethroplasty Strictures in Maiduguri, North Eastern Nigeria. Urology, 2012, Article ID: 847870. https://doi.org/10.5402/2012/847870 